\title{
Anne Buttimer, geògrafa (1938-2017). Innovació, creativitat i interdisciplinarietat
}

Anne Buttimer va morir el 17 de juliol de 2017. Molt poca gent sabia que estava malalta $i$, per això mateix, la notícia del seu traspàs va causar un gran impacte en la comunitat geogràfica. Ella, però, ja ens havia advertit del seu estat de salut en una carta enviada el Nadal de 2016 a les seves amistats. Tanmateix, es tractava d'una breu nota fora del cos principal de la carta, com aquell qui no diu res, sense cap tipus de dramatisme. Rellegint ara aquella missiva, farcida d'explicacions sobre els seus viatges acadèmics realitzats al llarg d'aquell any, ens adonem del missatge subliminal que ens enviava... Viatgera $i$ activa fins l'últim moment, la malaltia va acabar vencent-la, no sense oposar-hi, però, una feroç resistència. No deixa de ser significatiu el títol d'un article que uns quants mesos abans va publicar en un número de la revista The Arab World Geographer dedicat als geògrafs jubilats: «Retirement?: You must be joking» (2016).

Anne Buttimer va néixer a Cork (Irlanda) l'any 1938. El 1957 aconseguí el BA en Geografia, Llatí i Matemàtiques a la universitat de la mateixa població. El 1959 va obtenir el màster en Geografia a la Universitat Nacional d'Irlanda i poc després entrà a formar part de l'orde dominicà, que li va concedir la dispensa el 1976. Uns quants anys abans, el 1965, s'havia doctorat a la Universitat de Seattle amb una aprofundida recerca sobre la tradició geogràfica francesa, tema central del llibre Society and Milieu in the French Geographic Tradition (1971), un autèntic referent en la matèria. No deixa de sorprendre que es doctorés tractant una temàtica com aquesta en un departament de geografia que en aquells moments era un dels baluards de la geografia quantitativa a nivell internacional.

Entre els anys 1965 i 1968 va combinar una beca postdoctoral a la universitat belga de Lovaina (on va cursar estudis de filosofia) amb una plaça de professora adjunta a Seattle. Entre 1968 i 1970 va ser docent d'Estudis Urbans a la Universitat de Glasgow, estada que ella sempre recordava amb estima, ja que va representar la seva incursió en el món de la planificació urbana tot aplicant-hi temes i idees provinents de la geografia social, que era el que realment l'interessava. Entre els anys 1970 i 1981 va ser professora a la Universitat de Clark (Massachussets, EUA), on va esdevenir catedràtica. Posteriorment, el 
1982, es traslladà a la Universitat de Lund, on va romandre fins l'any 1989 en qualitat de becària de recerca del Consell Suec d'Humanitats i Ciències Socials. Lund ja li era familiar, atès que hi va realitzar una estada el 1976 convidada per Torsten Hägerstrand. Aquests anys a la Universitat de Lund van ser decisius en molts sentits, tant a nivell professional (aquí és on comença el seu magne Projecte de Diàleg Internacional, del qual parlarem més endavant), com a nivell personal, atès que s'hi va casar amb Bertran Broger, catedràtic de Mecànica Sòlida de la mateixa institució docent. Després d’una estada a la Universitat d'Ottawa entre els anys 1989 i 1991, tornà a la seva Irlanda natal i va ocupar una càtedra a la Universitat de Dublín, on va continuar fins que es va jubilar, el 2003, i d'on posteriorment va ser professora emèrita.

Valorar en un breu obituari l'extraordinària aportació d'Anne Buttimer a la geografia no és facil. Geògrafa poliglota, gran viatgera i amb una formació cultural amplíssima, la seva contribució a la geografia social i humanística ha estat cabdal, com també ho ha estat la seva recerca en l'àmbit del pensament geogràfic i de la història de la geografia. Va publicar innombrables articles i molts llibres, una bona part dels quals van ser traduïts a diversos idiomes. Anne Buttimer va ser una de les veus més crítiques al neopositivisme imperant en la geografia anglosaxona a la dècada de $1970 \mathrm{i}$ una de les iniciadores i principals impulsores de l'anomenada "geografia humanística», denominació que mai la va acabar de convèncer del tot. Sempre, però, va reconèixer el lideratge de $\mathrm{Yi}-\mathrm{Fu}$ Tuan en aquest corrent $\mathrm{i}$ la influència que en va rebre en els seus inicis (Maddrell, 2009). La rellevància que Buttimer donava al tema dels «valors» en geografia ja es posa de manifest en un dels seus primers escrits (de principis de la dècada de 1970), editat per l'Associació de Geògrafs Americans amb un ressò més que notable (1974). Poc després publicava The Human Experience of Space and Place (Buttimer i Seamon, 1980), un volum on recollia els treballs dels seus estudiants de doctorat de Clark, molts dels quals esdevindrien noms rellevants en aquest corrent uns quants anys més tard. En aquesta línia, un dels articles que va tenir més impacte i un dels més citats fou "Grasping the Dynamism of Lifeworld», editat als Annals of the Association of American Geographers (1976).

De mentalitat oberta, la geografia social de Buttimer es mostrava molt receptiva cap a temes com ara el gènere i el feminisme en geografia, encara que no hi hagués treballat directament. Com afirma Maddrell (2009: 741): «si bé Buttimer no es pot considerar una teòrica feminista per se, el seu treball ens mostra una sensibilitat pel gènere a través de la seva preocupació per la perspectiva humanista en la forma d'entendre la geografia i el coneixement». Certament, mostrava simpatia per aquesta qüestió ja des de la seva estada a la Universitat de Clark, on tant la geografia radical com la geografia feminista eren ben conegudes, tal com quedava reflectit en els primers números de la revista Antipode, publicada en aquesta mateixa universitat i per a la qual Buttimer va escriure uns quants articles. A l'entrevista que uns quants anys més tard li faria Avril Maddrell es refereix de forma molt laudatòria a la tasca portada a terme per la Comissió de Geografia i Gènere de la UGI, on potser s'hagués 
integrat si no hagués estat tan compromesa amb la Comissió de Pensament Geogràfic, a la qual va dedicar moltíssims esforços.

El pensament geogràfic, en efecte, va ser un dels seus camps de treball prioritaris. És impossible resumir en aquesta breu nota les seves aportacions respecte a aquesta temàtica. No podem deixar de recordar, però, dues obres en les quals queda palesa la importància que donava al context en l'estudi del pensament geogràfic i de la seva evolució històrica. Ens referim a Text and Image: Social Construction of Regional Knowledge i Nature and Identity in Cross-cultural Perspective (Buttimer et al., 1999a; Buttimer i Wallin, 1999b).

Una altra de les seves aportacions cabdals en aquest àmbit de recerca és el macroprojecte d'investigació anomenat Projecte de Diàleg Internacional, iniciat durant la seva estada a la Universitat de Lund juntament amb Torsten Hägerstrand. Es tractava d'una iniciativa molt ambiciosa, de llarga durada, internacional i interdisciplinària, en què van intervenir més de 200 col-legues de disciplines ben diverses i de 35 països diferents. Es perseguia treure a la llum allò que era comú i compartit en àmbits de coneixement aparentment allunyats, per tal d'arribar a una comprensió mútua i a una comunicació millor entre els experts. Òbviament, la geografia hi tenia un gran pes específic, com queda reflectit en obres àmpliament citades i reconegudes, com ara The Practice of Geography (1983) o Geography and the Human Spirit (1993).

Anne Buttimer va exercir una influència notable en la geografia catalana i espanyola, ja des dels inicis de la seva carrera acadèmica. Val la pena recordar aquí que el seu llibre Society and Milieu in the French Geographic Tradition (1971) va ser traduït el 1980 per l'editorial Oikos-Tau a iniciativa d'Enric Lluch i ben aviat es va convertir en un referent (1980). Encara avui és una obra àmpliament utilitzada en cursos d'història del pensament geogràfic. La relació, però, no va ser a distància, sinó ben personal, en particular amb els autors d'aquestes línies, Maria Dolors Garcia Ramon i Joan Nogué. Amb la primera es van conèixer a la Universitat de Clark el 1975 arran d'una estada postdoctoral de qui signa aquestes línies. Va assistir a les seves classes de pensament geogràfic i als seminaris que organitzava sovint al seu domicili particular, just al davant de la Universitat (a la Main Road de Worcester). Fruit d'aquesta relació n'és la seva primerenca visita a la UAB, el maig de 1976, quan Buttimer gaudia d'una beca Fulbright a la Universitat de Lund. Aquella va ser la primera d'una llarga quantitat de visites i d'estades que, a partir de llavors, faria a Catalunya i a Espanya, en concret a Madrid, per invitació dels col-legues de les universitats Complutense i Autònoma de Madrid. Potser una de les seves visites més fructíferes a terres catalanes va ser la que va realitzar l'agost de 1986 amb motiu de la reeixida reunió de la Comissió de Pensament Geogràfic de la UGI en el marc de la celebració de la Conferència Regional per part d'aquesta universitat al Palau de Congressos de Barcelona (organitzada, al seu torn, pel Departament de Geografia de la Universitat de Barcelona i en especial pel Dr. Vilà Valentí, en aquells moments vicepresident de la UGI).

Els lligams personals i professionals dels autors del present escrit amb Anne Buttimer es van anar enfortint amb el temps, no només, per exemple, a través 
del seu consell i assessorament per tal que Joan Nogué es desplacés a la Universitat de Wisconsin-Madison el 1987 per realitzar una estada postdoctoral sota la tutela de Yi-Fu Tuan, o que Maria Dolors Garcia Ramon es traslladés a la Universitat d'Arizona el curs 1988-1989, sinó també a través de projectes de recerca compartits. Ens referim, en concret, a la participació en el ja mencionat Projecte de Diàleg Internacional. En efecte, mercès a un ajut de la llavors coneguda com a Comissió Interdepartamental de Recerca i Innovació Tecnològica (CIRIT) de la Generalitat de Catalunya, es va endegar al Principat un programa d'investigació similar i en estret contacte amb l'impulsat des de la Universitat de Lund. A més dels signants d'aquest text, s'integraren en l'equip Abel Albet i Mireia Belil. Poc després, el 1989, el projecte prengué més volada gràcies a un ajut de recerca de la Direcció General d’Investigació Científica i Tècnica (DGICYT) del Ministeri d'Educació i Ciència espanyol. Amb aquest nou suport financer es portà a terme el programa de recerca «La innovació metodològica en la geografia espanyola en el període 1940-1990", d'on se'n derivaren diverses publicacions, d'entre les quals ressaltaríem el llibre La práctica de la geografía en España (1940-1990): Innovación metodológica y trayectorias individuales en la geografia académica española (Garcia Ramon et al., 1992). La similitud del títol amb el de l'obra The Practice of Geography (1983) d'Anne Buttimer no és casual: els objectius i la metodologia eren similars, però aplicats al cas espanyol. S'establí, per tant, una intensa i fructífera col-laboració amb l'equip dirigit per Anne Buttimer des de Lund, que va donar moltíssims fruits, entre d'altres, podríem parlar de l'intercanvi d'entrevistes personals enregistrades en vídeo als principals protagonistes del pensament geogràfic contemporani, català i espanyol en el nostre cas i de molts altres països.

En els últims anys, les visites d'Anne Buttimer a Barcelona estaven relacionades amb el Centre Mediterrani que l'Acadèmia Europea havia establert a Barcelona, en concret a la seu de l'Institut d'Estudis Catalans. Anne Buttimer va ser vicepresidenta de l'Acadèmia Europea des de 2013, després d'haver estat presidenta de la Secció de Ciències Socials durant un temps. Precisament en una d'aquestes visites, el desembre de 2015, al Cercle del Liceu, Alex Fidora li va fer l'entrevista en vídeo mencionada més amunt, la darrera de la qual tenim constància i per aquesta raó ha adquirit un valor especial (<https://vimeo. com/174565743>).

Anne Buttimer va mantenir sempre i fins l'últim moment aquesta dimensió internacional. No només va ser investigadora i professora en diversos països a banda i banda de l'Atlàntic, sinó que també va treballar molt en entitats de caràcter mundial, com ara la Unió Geogràfica Internacional (UGI), de la qual va ser elegida vicepresidenta l'any 1996 i presidenta del 2000 al 2004, la primera dona que va ostentar aquest càrrec en la història d'aquesta institució. Prèviament havia format part de la Comissió de Pensament Geogràfic de la pròpia UGI, dinamitzant-la amb moltíssimes iniciatives, com ara la sèrie "Geographers. BioBibliographical Studies», un referent encara avui. Per aquesta intensa activitat internacional i també per la vàlua de la seva obra, Anne Buttimer ha estat durant molts anys una de les geògrafes més conegudes $\mathrm{i}$ citades 
internacionalment, juntament amb Doreen Massey, que ens va deixar un any abans, el 2016.

Al llarg de la seva vida va rebre nombrosos reconeixements, tant nacionals com internacionals, entre els quals ressalten el premi Ellen Semple de la Universitat de Kentucky, el 1991; el Premi Centennial, de la Reial Societat Geogràfica britànica el 2001, i la Medalla d'Or de la Societat Sueca d'Antropologia i Geografia, el 2009. Més recentment, l'any 2014, va rebre el Lifetime Achievement Award, de l'Associació de Geògrafs Americans, així com el premi Vautrin Lud, conegut col-loquialment com el Premi Nobel de la geografia.

L'obra d'Anne Buttimer és complexa, multidimensional i molt sòlida intellectualment. Va ser una geògrafa excepcional, amb una capacitat de treball poc habitual i amb una base cultural amplíssima. Sempre amb una actitud oberta a nous plantejaments metodològics i epistemològics, no és estrany que, ara mateix, s'estableixi una clara connexió entre el seu pensament i el dels joves impulsors de la nova i reeixida revista Geohumanities, per posar-ne només un exemple. Per tirar endavant una iniciativa tan ambiciosa com el Projecte de Diàleg Internacional cal ser una persona amb una erudició immensa i, alhora, amb una gran sensibilitat, capaç de captar l'essència i la similitud de discursos aparentment —només aparentment— oposats i suposadament divergents. Vet aquí l'elegància i l'essència que desprèn l'ikebana que encapçala el llibre The Practice of Geography (1985). Hi ha una reflexió seva en la introducció d'aquest llibre que ben bé li podríem aplicar a ella mateixa i que podria servir de colofó a aquestes paraules de gratitud $\mathrm{i}$ reconeixement:

In each person's life echoes the drama of his or her times and milieu; in all, to varying degrees, the propensity to submit or rebel. Through our own biographies we reach toward understanding, being and becoming. (p. 3)

\section{Referències bibliogràfiques}

ButTIMER, Anne (1971). Society and Milieu in the French Geographic Tradition. Chicago: RandMcNally. Traducció al castellà: Sociedad y medio en la tradición geográfica francesa. Barcelona: Oikos-Tau, 1980.

- (1974). Values in Geography. Washington: AAG Comission on College Geography, Resource Paper, 24. <https://doi.org/10.1177/030913259602000405>

- (1976). "Grasping the Dynamism of Lifeworld». Annals of the Association of American Geographers, 66 (2), 277-292.

<https://doi.org/10.1111/j.1467-8306.1976.tb01090.x>

- (1983). The Practice of Geography. Londres: Longmans.

- (1993). Geography and the Human Spirit. Baltimore: The Johns Hopkins University Press.

- (2016). «Retirement?: You Must Be Joking». The Arab World Geographers, 19 (1-2), 27-37.

<https://doi.org/10.1145/1232919.1232931> 
Buttimer, Anne; Brunn, Stantley D. i WardengA, Ute (1999a) (eds.). Text and Image: Social Construction of Regional Knowledges. Leipzig: Institute für Länderskunde.

ButTimer, Anne i SEAmOn, David (1976). The Human Experience of Place and Space. Londres: Croom Helm Publishers.

- (1980). The Human Experience of Space and Place. Abingdon, Oxon: Routledge.

ButTimer, Anne i Wallin, Luke (1999b) (eds.). Nature and Identity in Cross-Cultural Perspective. Dordrecht: Kluwer.

Garcia-Ramon, Maria Dolors; Nogué, Joan i Albet, Abel (1992). La práctica de la geografía en España. Barcelona: Oikos-Tau.

MADDRELL, Avril (2009). «An Interview with Anne Buttimer: An Autobiographical Window on Geographical Thought and Practice 1965-2005». Gender, Place and Culture, 16 (6), 741-765.

<https://doi.org/10.1080/09663690903279179>

Maria Dolors Garcia-Ramon

Universitat Autònoma de Barcelona mariadolors.garcia.ramon@uab.es

Joan Nogué

Universitat de Girona joan.nogue@udg.edu 